\title{
OMNISCIENCIA Y FUTUROS CONTINGENTES: UN COMENTARIO LÓGICO
}

RAÚL ORAYEN

Instituto Torcuato $\mathrm{Di}$ Tella, Argentina

En su trabajo "Omnipotencia, omnisciencia y libertad", Eugenio Bulygin desarrolla varios argumentos interesantes para defender la consistencia lógica de ciertas proposiciones teológicas y su compatibilidad con algunos elementos de juicio aparentemente adversos (por ejemplo, la existencia del mal). Especialmente agudos y convincentes son sus argumentos en contra de Mackie. En una etapa posterior del artículo, Bulygin apoya sus planteos en el rechazo de una tesis semántica que puede formularse así: los enunciados acerca de hechos futuros tienen un valor de verdad definido. En lo que sigue, llamaré 'DS' (por 'determinismo semántico') a esta tesis. Bulygin no acepta la validez irrestricta de DS por cuanto sostiene la siguiente tesis contrapuesta: los enunciados acerca de hechos futuros que no están determinados ni lógica ni causalmente (los llamados "futuros contingentes") carecen de valor de verdad. En adelante, 'FC' denotará esta otra tesis. FC es una proposición controvertible y su uso por parte de Bulygin debilita su posición. ${ }^{2}$ En lo que sigue, sin embargo, me propongo mostrar que modificando ligeramente la argumentación de Bulygin puede llegarse a sus mismos resultados sin usar FC (ni adoptar otros supuestos en su reem. plazo). Primero será necesario recordar brevemente cómo usa Bulygin la premisa FC.

1 Este texto reproduce un comentario sobre el trabajo "Omnipotencia, omnisciencia y libertad", de Eugenio Bulygin, formuladó en ocasión de su presen. tación en la Sociedad Argentina de Análisis Filosófico, en la reunión del 4 de septiembre de 1976.

2 Puede observarse que FC es el blanco principal de las observaciones críticas que formula Juan Larreta en su comentario sobre el trabajo de Bulygin. 
En la sección 2 del artículo, Bulygin muestra eficazmente que la existencia del mal y la posibilidad lógica de un mun. do mejor que el real (el mundo de Mackie) pueden resultar compatibles con las proposiciones teológicas analizadas (que, entre otras cosas, afirman la existencia de un Dios omnipotente, omnisciente y bueno). Para alcanzar este objetivo, Bulygin concede al teólogo un supuesto básico: la existencia de la libertad humana. ${ }^{3}$ Surge entonces otro problema: ¿es la omnisciencia divina compatible con tal libertad? El siguiente argumento sugiere lo contrario: si Dios es omnisciente, conoce las acciones futuras de los hombres. Dios sabe, por ejemplo, que Pérez devolverá mañana un portafolios. En ese caso, observa Bulygin, "parece que Pérez no puede dejar de devolverlo y su acción no es, por lo tanto, libre" (énfasis mío). En efecto, si Pérez no devolviera el portafolios se volvería falsa una proposición conocida por Dios, lo cual choca con el significado de 'conocer'.

Bulygin resuelve el problema de manera drástica. En primer lugar, adopta la premisa FC. En segundo lugar, reconoce que la libertad humana impide a Dios conocer las futuras acciones de los hombres (en general, reconoce que Dios no puede conocer "futuros contingentes"). Pero aduce que esta limitación del conocimiento divino no afecta su omnisciencia, ya que una definición adecuada de 'ser omnisciente' sólo podría exigir que un ser tal conociera todo lo cognoscible. Y de acuerdo con FC las proposiciones sobre futuros actos humanos libres no tienen valor de verdad y son en consecuencia incognoscibles. FC, por un lado, y la razonable restricción impuesta al significado de 'omnisciente', por otro,

3 Un determinista aduciría que este supuesto es más controvertible que FC. Debe observarse, sin embargo, que su aceptación es muy razonable en el contexto en que lo usa Bulygin. Recordemos que el tema de su trabajo es la consistencia o inconsistencia de ciertas tesis teológicas. Pero el supuesto de la libertad es otra tesis teológica tradicionalmente asociada a las primeras. Resulta natural, entonces, admitirla como hipótesis e investigar la consistencia del conjunto que forma con las otras tesis estudiadas. Obsérvese que justamente esto es lo que hace Bulygin en el trabajo. El caso de FC es distinto: es una tesis semántica "externa", no relacionada históricamente con la aceptación de las otras proposiciones (teológicas) analizadas. 
permiten compatibilizar omnisciencia divina y libertad $h u$ mana. Veremos a continuación cómo alcanzar resultados similares sin la premisa $\mathrm{FC}$.

En sus razonamientos, Bulygin supone implícitamente que si un enunciado satisface la tesis DS se sigue de ello que satisface una tesis sobre la existencia de un determinismo causal (en adelante, 'DC'). En otras palabras, Bulygin cree que si un enunciado acerca de un hecho futuro (lógicamente contingente) posee un valor de verdad definido, se sigue de ello que el hecho está determinado causalmente (si el enunciado es verdadero) o está determinado causalmente que el hecho no ocurrirá (si el enunciado es falso). (En adelante, sintetizaremos esta tesis mediante la formulación 'DS implica DC'.) ¿Existe realmente esta conexión lógica? Sin pronunciarnos sobre el punto, construiremos un dilema cuya premisa principal será la siguiente proposición:

(1) O bien DS implica lógicamente DC o bien no existe tal conexión lógica. La proposición (1) es una premisa insospechable, porque constituye un caso de la ley de tercero excluído. Pero veremos ahora que cada una de sus disyuntivas conduce a la conclusión defendida por Bulygin.

Supongamos que DS implica lógicamente DC. Por contraposición, se sigue que si un hecho futuro (lógicamente contingente) no está determinado causalmente, un enunciado que lo describa ahora no tiene valor de verdad. Por definición, un acto libre no está determinado causalmente. Luego, los enunciados que describen futuros actos humanos libres carecen de valor de verdad. Luego, tales enunciados son incognoscibles y Dios no los conoce, pero sin menoscabo de su omnisciencia, debido a las razones aducidas por Bulygin. En esta alternativa, la libertad no está reñida con la omnisciencia.

Supongamos ahora que DS no implica DC. En ese caso, no solamente resultan compatibles la libertad y la omnisciencia, sino que Dios puede conocer futuros actos humanos libres, sin que ello conduzca a contradicción. En efecto, su- 
pongamos que Dios sabe ahora que Pérez devolverá el portafolios mañana. Si Dios tiene tal conocimiento, el enunciado acerca de Pérez tiene un valor de verdad definido: verdad. Pero si DS no implica lógicamente $\mathrm{DC}$, no se sigue de esto que el acto de Pérez esté determinado causalmente, y el conocimiento divino no se opone a su libertad. ${ }^{*}$

En el dilema anterior se llega a la conclusión de Bulygin sin agregar nuevas premisas a las suyas, y eliminando FC. Puede observarse que el argumento original de Bulygin coincide esencialmente con la parte del dilema en que se supone que $D S$ implica $D C$. La coincidencia no es casual: suponer la existencia de tal implicación es interdeducible con la tesis FC, base de su argumentación.

Por razones que expongo en otro lugar, no creo que se pueda demostrar concluyentemente la consistencia de las tesis teológicas analizadas por Bulygin. Sin embargo, puede acumularse evidencia importante en favor de tal consistencia mediante una vía negativa: mostrando que son inadecuados diversos argumentos que pretenden demostrar la inconsistencia de las tesis estudiadas. La argumentación de Bulygin es de este tipo y creo que "depurada" del supuesto FC suministra elementos de juicio poderosos en favor de las conclusiones defendidas en su trabajo.

- Más arriba sintetizamos un argumento de Bulygin que intentaba mostrar la imposibilidad lógica del conocimiento previo de un acto libre. Obsérvese que en ese argumento era crucial la aceptación de que DS implica DC. En efecto, del hecho de que Dios conociera una acción futura de Pérez, infería Bulygin (correctamente) que determinada proposición debía ser verdadera. De esto infería luego que el hecho correspondiente estaba causalmente determinado. En este último paso se supone que DS implica DC. 